\title{
Multibeam echosounder observations reveal interactions between Antarctic krill and air-breathing predators
}

\author{
Martin J. Cox ${ }^{1, *}$, David A. Demer ${ }^{2}$, Joseph D. Warren ${ }^{3}$, George R. Cutter ${ }^{2}$, \\ Andrew S. Brierley ${ }^{1}$ \\ ${ }^{1}$ Pelagic Ecology Research Group, Gatty Marine Laboratory, University of St. Andrews, Fife KY16 8LB, UK \\ ${ }^{2}$ Advanced Survey Technology Program, Southwest Fisheries Science Center, 8604 La Jolla Shores Drive, La Jolla, \\ California 92037, USA \\ ${ }^{3}$ School of Marine and Atmospheric Sciences, Stony Brook University, 239 Montauk Highway, Southampton,
} New York 11968, USA

\begin{abstract}
A multibeam echosounder (MBE) was deployed on an inflatable boat (length $=5.5 \mathrm{~m}$ ) to observe swarms of Antarctic krill Euphausia superba in the nearshore environment off Livingston Island, South Shetland Islands, Antarctica. Visual observations of air-breathing predators, including penguins and fur seals, were made from the boat at the same time. MBEs extend the 2-dimensional acoustic observations that can be made with conventional vertical echosounders to 3 dimensions, enabling direct observation of the surface areas and volumes of entire krill swarms. Krill swarms exhibited a wide range of various size metrics (e.g. height, length and width) but only a narrow range of surface-area-to-volume ratios or 'roughnesses', suggesting that krill adopt a consistent group behavior to maintain swarm shape. The variation in $R$ was investigated using generalized additive models (GAMs). GAMs indicated that the presence of air-breathing predators influenced swarm shape ( $R$ decreased as the range to predators decreased, and the swarms became more spherical), as did swarm nearest-neighbor distance ( $R$ decreased with increasing distance) and swarm position in the water column ( $R$ decreased in the upper $70 \%$ of the water column). Therefore, swarm shape appears to be influenced by a combination of behavioral responses to predator presence and environmental variables. MBEs have the potential to contribute much to studies of krill, and can provide data to improve our understanding of the behavior of krill in situ.
\end{abstract}

KEY WORDS: Antarctic krill · Euphausia superba · Predator-prey interactions · Multibeam echosounder $\cdot$ Swarm morphology $\cdot$ Livingston Island

\section{INTRODUCTION}

Antarctic krill play a pivotal role in the Southern Ocean ecosystem (Mangel \& Nicol 2000, Atkinson et al. 2001) but are difficult to sample because of their extremely patchy distribution: much krill biomass is contained in a few high-density swarms (Brierley et al. 1999, Hofmann et al. 2004) that may be undersampled during surveys with conventional narrow-beam echosounders along widely spaced transects. Managing krill resources, particularly in an ecosystem context, requires data on the patterns of temporal and spatial interactions between krill and the many predators that depend on them, but efforts to gather requisite data at sea have been hampered because of major difficulties in sampling krill over appropriate scales (Logerwell et al. 1998, Hewitt \& Demer 2000). Attempts to link the distributions of krill and their predators from observations along survey transects may have been unsuccessful because the downward-looking echosounders used 
to routinely estimate krill abundance (Hewitt et al. 2004), fail to detect krill swarms just off the survey track line. Research by Zamon et al. (1996), using a smallscale $\left(1852 \mathrm{~m}^{2}\right)$, line-transect grid (transect spacing ca. $300 \mathrm{~m}$ ) suggests that predators observed visually in the vicinity of the research vessel may be feeding upon these undetected krill swarms, leading to spatial mismatch in the krill-predator observations. Conventional single-beam echosounders (SBEs) sample only a narrow cone of water (typically $7^{\circ}$ ) beneath the research vessel. For a vessel with a draft of $5 \mathrm{~m}$ this provides a window of observation just $3 \mathrm{~m}$ wide at $30 \mathrm{~m}$ depth: visual observations of predators on the other hand may span tens or hundreds of meters either side of the vessel. Multibeam echosounders (MBEs) sample a wider swath (e.g. 90 to $120^{\circ}$ ) and extend greatly the observation to the sides of the survey track: for example in $100 \mathrm{~m}$ of water a $120^{\circ}$ swath may sample within a range of $173 \mathrm{~m}$ to either side of the survey track. Thus, the 2-dimensional (2D) view provided by SBEs is effectively extended into 3 dimensions (3D; Gerlotto et al. 1999) by MBEs, offering the potential to examine finescale interactions (sensu Zamon et al. 1996).

The sampling volume differences between SBEs and MBEs arise due to the way each instrument samples the water column. The 1-dimensional observations from an SBE of the acoustic mean volume backscattering strength $\left(S_{\mathrm{v}}\right.$, logarithmic measure, units $\left.\mathrm{dB}\right)$ down the water column are combined over adjacent pings (a transmit and receive cycle; a typical ping rate is $1 \mathrm{~s}^{-1}$ ) and are used to build up a 2D matrix from a narrow slice of the water column along the survey track (Reid \& Simmonds 1993). In contrast, a single ping from an MBE (Fig. 1) samples a swath through the water column across the survey track. Each swath is made up of observations from multiple acoustic beams that radiate from a central point, with the position of each $S_{\mathrm{v}}$ observation within a swath being described in 2D in terms of a range and bearing from the origin. By combining successive swaths, a 3D acoustic image of the water column along and to either side of the survey track can be created.

MBEs have been used to investigate predator-prey interactions, for example between Atlantic puffins Fratercula arctica and herring Clupea harengus (Axelsen et al. 2001). Gerlotto \& Paramo (2003) used MBEs to investigate the geometry of pelagic aggregations of the clupeid Sardinella aurita. MBEs have also been used to study the 3D structure and vessel avoidance behavior of anchovy Engraulis ringens and common sardine Strangomera bentincki schools (Gerlotto et al. 2004), and to assess the 3D school structure of clupeids S. aurita and Sardinops sagax (Paramo et al. 2007).

The objectives of the present study were to (1) examine the utility of an MBE for observations of Antarctic krill, and (2) use an MBE to improve our
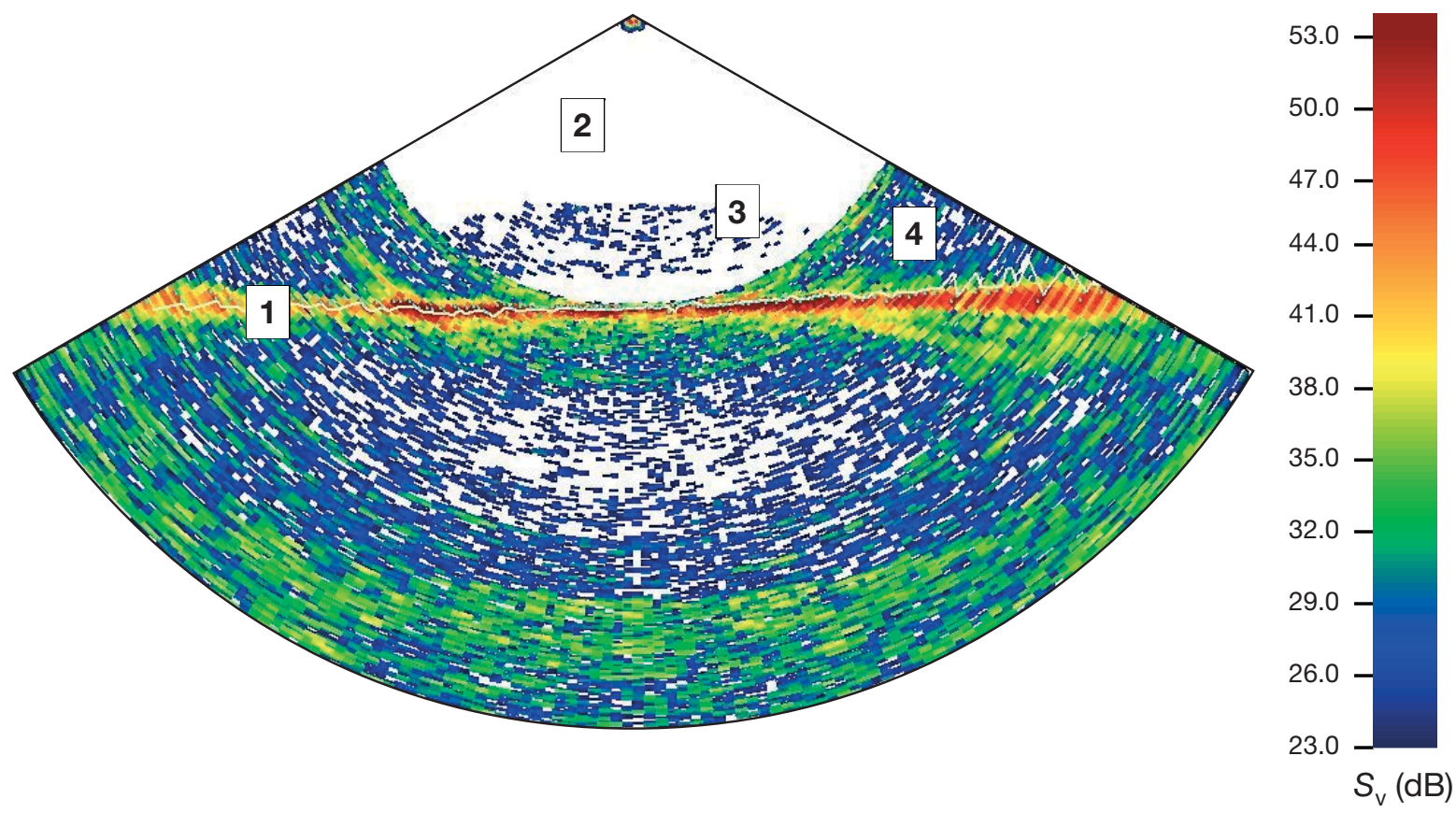

Fig. 1. A single multibeam echosounder $(\mathrm{MBE})$ ping (range $=200 \mathrm{~m}$ ), showing acoustic mean volume backscattering strength $\left(S_{\mathrm{v}}, \mathrm{dB}\right.$, uncalibrated) $S_{\mathrm{v}}$ values from 23 to $53 \mathrm{~dB}$. Numbers identify the following features: $1=$ the MBE seabed profile; $2=$ the effective sampling volume; 3 = a krill swarm; and 4 = seabed side lobe detections that limited the sampling volume 
understanding of interactions between krill and predators at the small to mesoscale (tens to thousands of meters). The acoustic reflectivity or target strength (logarithmic measure, units $\mathrm{dB}$ ) of krill is approximately 1000 times less than that of the fish that have previously been observed using MBEs. For example, at $120 \mathrm{kHz}$, the target strength of a $38 \mathrm{~mm}$ long krill is approximately $-77 \mathrm{~dB}$ (Demer \& Conti 2005), compared to about $-43 \mathrm{~dB}$ for a $21 \mathrm{~cm}$ long herring (Gorska \& Ona 2003). Although theory indicates that krill should be detectable with an MBE, the first objective was to achieve a practical demonstration of krill observations in the Southern Ocean. The second objective involved using the large sampling volume and the 3D imaging capabilities of the MBE to examine possible relationships between krill swarms and predators, to determine for example if predators foraged in regions with an elevated number of krill swarms. To achieve these objectives we evaluated the utility of an MBE for studying at-sea predatorprey interactions by comparing MBE and SBE observations. In addition, using MBE and predator observations in a generalized additive modeling (GAM) framework, we estimated the spatial scales at which air-breathing krill predators and krill interacted, and investigated the influence predators may have had on krill swarm shape.

The observations reported here were made near Cape Shirreff in the vicinity of Livingston Island $\left(62.6^{\circ} \mathrm{S}, 60.3^{\circ} \mathrm{W}\right)$, South Shetland Islands, Antarctica (Fig. 2). The reproductive season of marine landbreeding animals, such as penguins and fur seals, at the South Shetland Islands lasts from November to March (Hewitt et al. 2003). During this time, large changes in krill wet mass density $\left(\mathrm{g} \mathrm{m}^{-2}\right)$ year-to-year have been recorded (e.g. varying from 1 to $60 \mathrm{~g} \mathrm{~m}^{-2}$ during 1992 to 2006; Hewitt \& Demer 1994, Hewitt et al. 2004, Reiss et al. 2008). Moreover, years when landbased predators exhibited reduced reproductive success coincided with years of low krill density (Hewitt et al. 2003).

During the reproductive season, the duration of foraging trips made by land-based predators are constrained by rearing and feeding requirements (i.e. most foraging effort is close to land by 'central place' foragers). It is therefore important to assess the density and spatial distribution of krill, and their physical oceanographic environment, in the nearshore area surrounding penguin and seal colonies, such as at Cape Shirreff. This information is required for ecosystem studies and also as a component of the holistic ecosystem approach to managing exploitation of living marine resources such as krill in a way that does not adversely affect dependent predators (Constable et al. 2000).

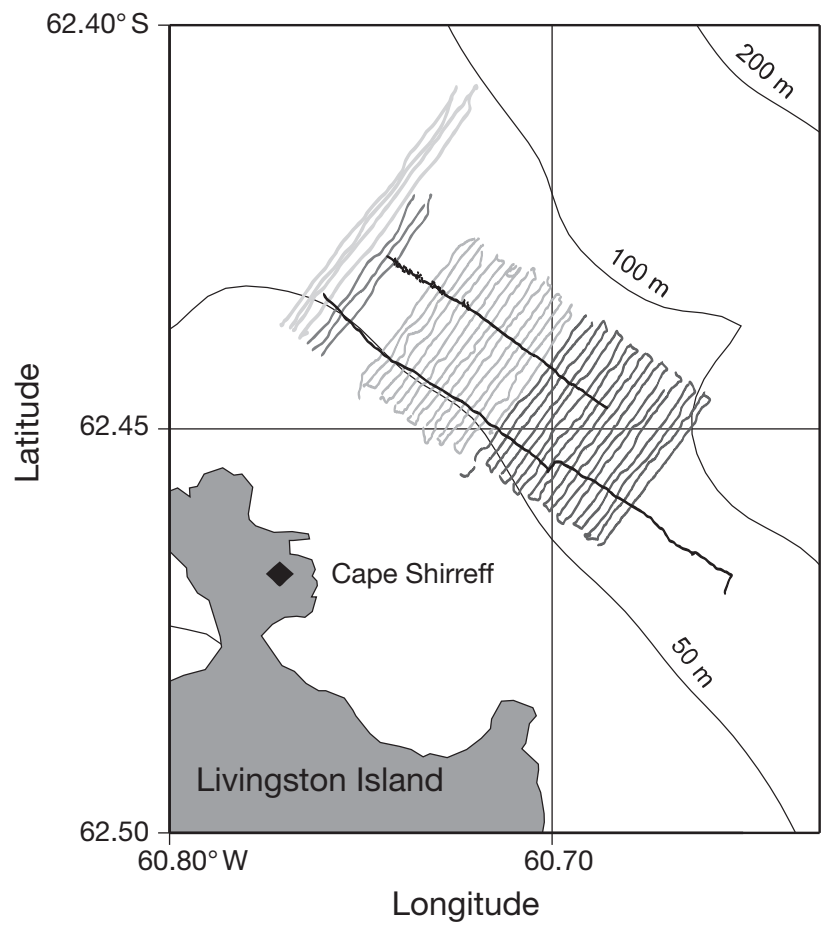

Fig. 2. Cape Shirreff study site, South Shetland Islands. Depth contours and MBE line transects within the MBE study area (grays indicate different observation days) are shown

\section{MATERIALS AND METHODS}

An inflatable boat, RV 'Roald' (Mark V Zodiac, length $5.5 \mathrm{~m})$, was deployed in the vicinity of Cape Shirreff, from 2 to 9 February 2006 (Fig. 2). RV 'Roald' (Fig. 3) was equipped with a Simrad Mesotech SM20, $200 \mathrm{kHz}$ MBE that was used to conduct a high-resolution bathymetry survey $(100 \%$ seabed coverage; depth accuracy $\pm 1 \mathrm{~m}, 95 \% \mathrm{CI}$ ) and to undertake simultaneous water column sampling to observe krill swarms acoustically. Between 4 and 8 February 2006, RV 'Roald' followed a systematic line-transect plan (Fig. 2). Each transect was either 2.5 or $3.5 \mathrm{~km}$ long, and line spacing was $120 \mathrm{~m}$.

Multibeam equipment and data description. The SM20 was configured with an 80-element array to create 128 receive beams, each with a $1.5^{\circ}$ across-track and $20^{\circ}$ along-track beam width, creating a total across-track swath width of $120^{\circ}$. An orthogonally mounted external transmit or profiling transducer was used to reduce the along-track beam width from $20^{\circ}$ to $1.5^{\circ}$, which improved the precision of locating targets in the water column and reduced between-ping, along-track acoustic-sampling-volume overlap. Assuming a flat seabed, the maximum swath width was approximately 3.5 times the water depth. The ping rate varied between 1.5 and 3 pings $\mathrm{s}^{-1}$; the time-varied gain correction was set to $20 \log _{10}(r)$, where $r$ is range 
from transducer; recording range was $200 \mathrm{~m}$, with a sampling resolution of $0.5 \mathrm{~m}$; pulse duration was $825 \mu \mathrm{s}$, and the transmission power was 'medium'.

The MBE was housed in a blister fairing (Fig. 3) mounted on a retractable frame which, when deployed, positioned the SM20 transducers along the center line of RV 'Roald', with the center beam of the MBE positioned vertically downward, giving a $60^{\circ}$ swath to both sides of the boat and perpendicular to the transect. This MBE orientation permitted simultaneous observations of the bathymetry and water column targets. The MBE observations were logged continuously to the SM20 control computer. Water column data $\left(S_{\mathrm{v}}\right.$ in $\mathrm{dB}$, for each $0.5 \mathrm{~m}$ sample) were converted to the SM2000 data format using a Simrad utility (MsToSm v1.0) and processed using Echoview v3.50 (SonarData). Krill swarms were identified using the 'cruise scanning 3D schools detection algorithm' developed by SonarData (see Cox et al. 2009 for sensitivity analysis of 3D detection parameters), and krill swarm metrics were extracted. Optimized swarm detection parameters were (1) processing threshold $=$ $24 \mathrm{~dB}$ (uncalibrated); and (2) minimum longest, middle and shortest dimensions $=5 \mathrm{~m}(\operatorname{Cox} 2008$, Cox et al. 2009).

The MBE operated at one frequency, so it was not possible to use multifrequency techniques (e.g. Brierley et al. 1998) to partition echoes by species. However, based on an analysis of multifrequency data obtained with a conventional scientific echosounder in the same

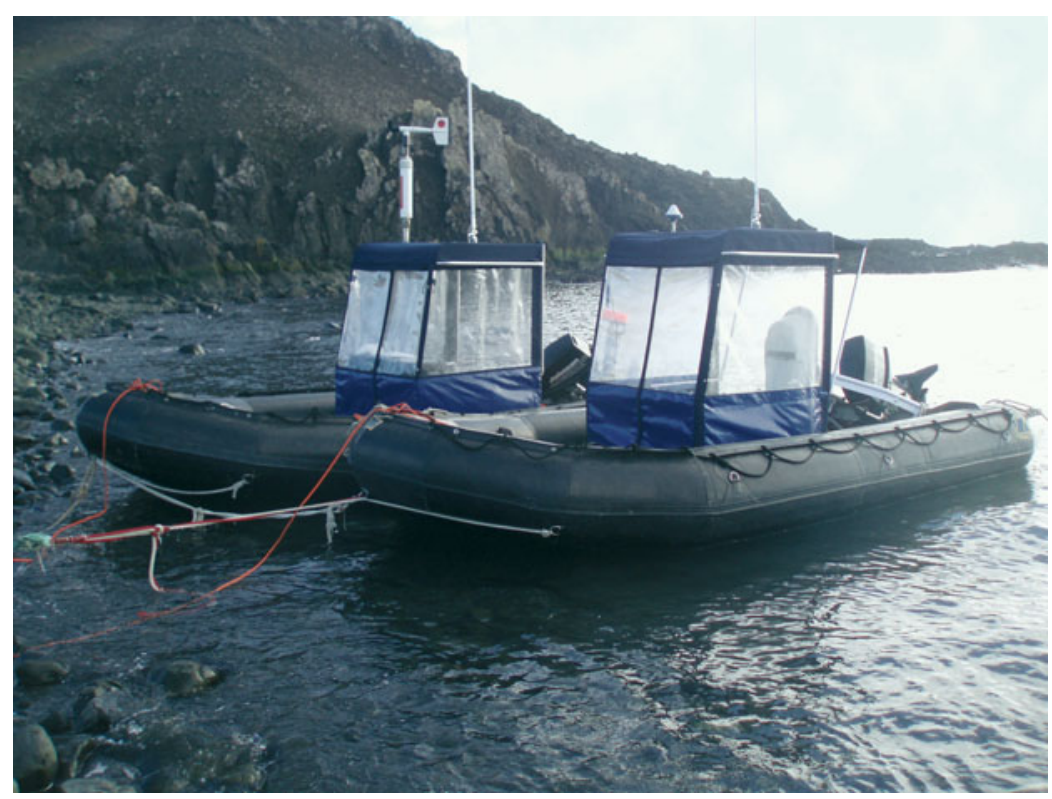

Fig. 3. The MBE-equipped RV 'Roald' (right-hand vessel) and single-beam echosounder (SBE)-equipped RV 'Ernest'. The MBE blister fairing (white) was mounted on a rotating frame attached to the Zodiac's transom (it is visible in the 'up' position through the transparent side of the dodger) area from a second inflatable boat (RV 'Ernest', lefthand vessel in Fig. 3), all MBE-detected aggregations were assumed to be krill swarms. The calibrated, dualfrequency (38 and $200 \mathrm{kHz}$ ) echosounder data (Simrad ES60) were collected by RV 'Ernest' within $5 \mathrm{~km}$ of the center of the multibeam study site (Fig. 2) and were analyzed following the methods of Brierley et al. (1998). That analysis indicated that $96.3 \%$ of the pelagic aggregations by number were indeed Antarctic krill swarms.

We sought to examine variability in krill swarm characteristics throughout the survey area. Simple linear measures of swarm dimensions may not accurately represent a swarm with a potentially complex shape. Linear measurements of water column aggregations are often based on a 3D bounding box placed around the aggregation. Such boxes only define an aggregation's maximum $x, y$ and $z$ dimensions (Gerlotto \& Paramo 2003). As an advance on this, the 3D shape of a krill swarm was further quantified here using the roughness $(R)$, calculated as the swarm surface area $(A)$ divided by its volume $(V)$. Following the procedure given in Gerlotto \& Paramo (2003), $R$ values for acoustically detected swarms were compared to those of 3 standard geometric shapes: a sphere; a cylinder, and an ellipsoid. To calculate the $R$ for these standard geometric shapes, the observed swarm $V$ values were used, and the $A$ values were calculated in the appropriate manner from $V$ for each shape: for spheres, $A$ values were calculated directly from the observed $V_{i}$ for cylinders, $A$ values were calculated from the observed $V$ and swarm heights $(H)$, and for ellipsoids, the lengths of the axes lengths and thus $A$ values were calculated from the dimensions of the 3D bounding box, measured using Echoview v3.5.

Predator-prey interactions. To assess the spatial overlap between air-breathing predators and krill, visual observations of predators were made from RV 'Roald' and RV 'Ernest', by a trained observer, concurrent with the multibeam sampling. Predators were detected forward of the protective dodger $(1 \mathrm{~m}$ back from the boat's bow, see Fig. 3) to a range of ca. $50 \mathrm{~m}$. Predator type, either swimming or flying, group size, activity (e.g. foraging, traveling), location and time of observation were recorded for the following predator species: Antarctic tern Sterna vittata; black-browed albatross Thalassarche melanophris; black-bellied storm petrel Fregetta tropica; chinstrap penguin Pygoscelis ant- 
arctica; Antarctic fur seal Arctocephalus sp. (gazella); gray-headed albatross Thalassarche chrysostoma; humpback whale Megaptera novaeangliae; south polar skua Catharacta maccormicki; giant petrel (unidentified) Macronectes sp.; penguin (unidentified) Pygoscelis/Eudyptes sp.; and Wilson's storm petrel Oceanites oceanicus. Bearing angles to predators were estimated using a compass, and ranges were estimated using marks on the dodger. Rapid and frequent changes in the boat heading due to waves probably introduced errors in some of the measurements of off-transect distances to predators.

The interactions between krill swarms and predators were investigated using predator sighting data observed from RV 'Roald' (see Table 2). Since there was no a priori reason to expect a linear response between swarm roughness and potential explanatory variables such as swarm or predator nearest-neighbor distance (NND) or seabed depth, GAMs were used to investigate the causes of variability in krill swarm roughness (analysis in R v2.4.0, mgcv library v1.3-19; R Development Core Team 2007). GAMs can be thought of as conventional regressions with the coefficients replaced by smooth functions, in this instance thin-plate regression splines, and are useful when relationships between explanatory and response variables are non-linear (Venables \& Dichmont 2004, Wood 2006). In the present study, a variety of combinations of explanatory variables were used, and the best GAM from a variety of candidate GAMs was selected in the conventional way on the basis of Akaike information criteria (AIC; Akaike 1974).

Variability in the number of krill swarms detected in the vicinity of a predator encountered by both boats was determined using an annulus sampler (Fig. 4). For each predator encounter, the number of krill swarms within a given area surrounding the position of a predator was calculated by laying down first a sampling circle of radius $=50 \mathrm{~m}$, followed by a series of concentric annuli with constant areas of $7854 \mathrm{~m}^{2}$ (equivalent to the area of a circle of radius $=50 \mathrm{~m}$, Fig. 4A). Consecutive sampling annuli were laid down at increasing ranges (Fig. 4B,C). Annuli more distant from the center had narrower inner to outer separations. The maximum total radius of this sampling was $274 \mathrm{~m}$ and comprised 30 sampling annuli. A GAM was fitted to the mean number of krill swarms detected in each annulus, at each sampling location. For each boat the total number of swarms in each sampling annulus was calculated for all predator encounters.

A simulation procedure was devised to examine potential differences between the number of krill swarms in the vicinity of predators and krill swarms in areas without predators. For each simulation, the annulus sampler, described above, was centered on $x$ randomly selected transect positions, where $x=41=$ the number of predator groups encountered. The simulation procedure was repeated 1000 times, and for each simulation a GAM was fitted to the mean number of krill swarms in each of the annulus sampling areas. The mean simulated GAM curves and associated standard errors were determined, and differences between the simulated and observed mean numbers of swarms were assessed using a 2-sample Kolmogorov-Smirnov test.

\section{RESULTS}

A total of 1084 krill swarms were detected by the MBE. Seabed depth in the survey area ranged from 20 to $140 \mathrm{~m}$; this is important to consider, as seabed depth
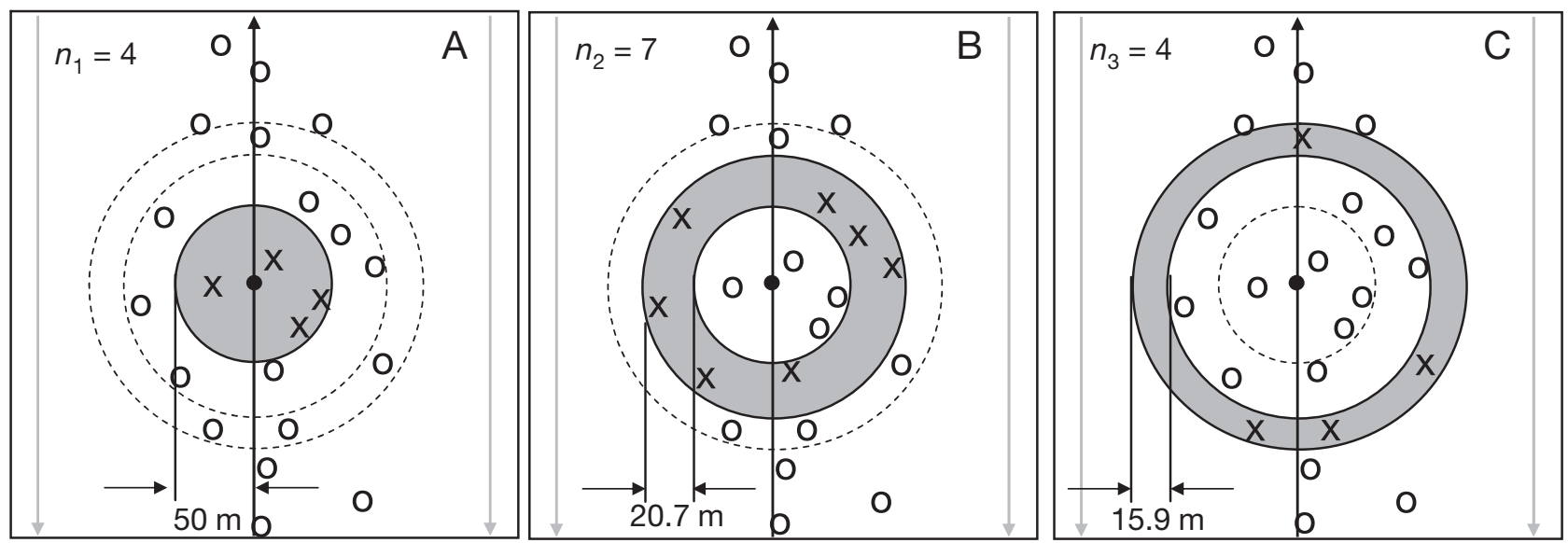

Fig. 4. Plan view of the annulus sampler (constant area $=7854 \mathrm{~m}^{2}$ ) defined around predator positions. (A) Circular sampling area $\left(n_{1}\right.$, radius $\left.=50 \mathrm{~m}\right)$ centered on an example predator location in which 4 predators were seen and, sequentially, the (B) first and 2nd concentric donuts $\left(n_{2}\right.$ and $\left.n_{3}\right)$ in which 7 and 4 predators were seen respectively. In this example, the sampling area is shown in gray, with krill swarms in the area $(\mathbf{X})$ and outside (O) 
Table 1. Summary statistics for the 1006 swarms that were located entirely within the multibeam echosounder swath. $A$ : surface area; $V$ : volume; $R$ : roughness; $S_{\mathrm{v}}$ : uncalibrated acoustic mean volume backscattering strength; posn $_{\mathrm{wc}}$ : position in the water column; CV: coefficient of variation

\begin{tabular}{|lcc|}
\hline Metric & Mean $(\mathrm{CV})$ & Range \\
\hline$A\left(\mathrm{~m}^{2}\right)$ & $11024.7(4.70)$ & $218.6-1222048$ \\
$V\left(\mathrm{~m}^{3}\right)$ & $3695.7(4.59)$ & $46.2-406709.8$ \\
$R\left(\mathrm{~m}^{-1}\right)$ & $3.3(0.23)$ & $1.2-8.1$ \\
$S_{\mathrm{v}}$ mean $\left(\mathrm{dB}\right.$ re $\left.1 \mathrm{~m}^{2} / \mathrm{m}^{3}\right)$ & $22.7(0.14)$ & $13.6-45.0$ \\
posn $_{\mathrm{wc}}$ & $0.6(0.32)$ & $0-1.0$ \\
\hline
\end{tabular}

Table 2. Foraging predators observed from RV 'Roald' in the multibeam study site and from RV 'Ernest' within $5 \mathrm{~km}$ of the center of the multibeam study site. unid.: unidentified

\begin{tabular}{|c|c|c|c|}
\hline \multirow{2}{*}{ Predator } & \multicolumn{2}{|c|}{ Number of individuals } & \multirow{2}{*}{$\begin{array}{l}\text { Predator } \\
\text { type }\end{array}$} \\
\hline & RV 'Roald' & RV 'Ernest' & \\
\hline $\begin{array}{l}\text { Sterna vittata } \\
\text { Antarctic tern }\end{array}$ & 10 & 7 & Flying \\
\hline $\begin{array}{l}\text { Thalassarche melanophris } \\
\text { black-browed albatross }\end{array}$ & 8 & 9 & Flying \\
\hline $\begin{array}{l}\text { Fregetta tropica } \\
\text { black-bellied storm petrel }\end{array}$ & 3 & 0 & Flying \\
\hline $\begin{array}{l}\text { Pygoscelis antarctica } \\
\text { chinstrap penguin }\end{array}$ & 1 & 6 & Swimming \\
\hline $\begin{array}{l}\text { Arctocephalus sp. (gazella) } \\
\text { Antarctic fur seal }\end{array}$ & 6 & 1 & Swimming \\
\hline $\begin{array}{l}\text { Thalassarche chrysostoma } \\
\text { gray-headed albatross }\end{array}$ & 0 & 4 & Flying \\
\hline $\begin{array}{l}\text { Megaptera novaeangliae } \\
\text { humpback whale }\end{array}$ & 4 & 7 & Swimming \\
\hline $\begin{array}{l}\text { Catharacta maccormicki } \\
\text { south polar skua }\end{array}$ & 2 & 0 & Flying \\
\hline $\begin{array}{l}\text { Macronectes sp. } \\
\text { giant petrel (unid.) }\end{array}$ & 1 & 9 & Flying \\
\hline $\begin{array}{l}\text { Pygoscelis/Eudyptes sp. } \\
\text { penguin (unid.) }\end{array}$ & 7 & 3 & Swimming \\
\hline $\begin{array}{l}\text { Oceanites oceanicus } \\
\text { Wilson's storm petrel }\end{array}$ & 12 & 12 & Flying \\
\hline
\end{tabular}

determines the MBE sampling volume and maximum observable across-track swarm width $(70 \mathrm{~m}$ at $20 \mathrm{~m}$ water depth and $485 \mathrm{~m}$ at $140 \mathrm{~m}$ water depth). MBE sampling volume is further reduced by side lobe detections of the seabed (Fig. 1), as krill swarms cannot be detected within the side lobe interference. Of the 1084 detected krill swarms, 78 were found to be truncated by side-lobe interference; thus 1006 krill swarms were determined to be entirely within the MBE effective sampling volume (Fig. 1) and used in subsequent analyses (Table 1).

During the survey, 41 foraging predator groups were encountered during the RV 'Roald' MBE survey, comprising a total of 54 individual predators (Table 2), of both swimming (18 ind.) and flying (36 ind.) types. During the RV 'Ernest' SBE survey, both swimming (17 ind.) and flying (41 ind.) predators were encountered within $5 \mathrm{~km}$ of the MBE study site. The predator type (swimming or flying) was used as a factor variable in the GAM investigating the variation in swarm roughness (Table 3).

\section{Swarm roughness}

The observed $R$ of krill swarms ranged from 1.2 to 8.1 (mean $R=3.3$; Table 1), and did not conform with the $R$ values expected for any of the simple geometric shapes considered: spheres have the lowest mean $R$ of 0.53, followed by cylinders (mean $R=$ 0.68 ), and then ellipsoids (mean $R=$ 2.0, Fig. 6). This suggests that krill swarm geometries cannot reliably be approximated by these simple shapes.

Table 3. Example candidate generalized additive models (GAMs) explaining swarm roughness. Explanatory variables considered in this example subset of candidate GAMs were swarm position in water column $\left(\right.$ posn $\left._{\mathrm{wc}}\right)$, mean swarm volume backscattering strength $\left(S_{\mathrm{v}}\right)$, nearest-neighbor distance between swarms $\left(N N D_{\text {swarm }}\right)$ and distance to nearest predator $\left(N N D_{\text {pred }}\right)$. Models were selected using Akaike information criteria (AIC). Model 1 was selected since the difference in AIC ( $\triangle$ AIC) between this model and model 2 was <2 (Burnham \& Anderson 2003), and this enabled examination of the potential influence of predator type (swimming or flying, pred) on $R$

\begin{tabular}{|c|c|c|c|c|c|}
\hline Model number & Explanatory variables & $\mathrm{r}_{\text {adj }}^{2}$ & Deviance explained (\%) & AIC & $\Delta \mathrm{AIC}$ \\
\hline 1 & $N N D_{\text {pred }}+N N D_{\text {swarm }}+p o s n_{\mathrm{wc}}+S_{\mathrm{v}}+$ pred & 0.56 & 51.3 & 1598.1 & +1.7 \\
\hline 2 & $N N D_{\text {pred }}+N N D_{\text {swarm }}+p o s n_{\mathrm{wc}}+S_{\mathrm{v}}$ & 0.56 & 51.3 & 1596.4 & 0 \\
\hline 3 & $N N D_{\text {pred }}+N N D_{\text {swarm }}+p o s n_{\mathrm{wc}}$ & 0.55 & 49.0 & 1634.0 & +37.6 \\
\hline 4 & $N N D_{\text {pred }}+N N D_{\text {swarm }}$ & 0.15 & 14.4 & 2092.8 & +496.4 \\
\hline 5 & $N N D_{\text {pred }}$ & 0.11 & 11.4 & 2121.2 & 524.8 \\
\hline
\end{tabular}


The low variance of $R$ is illustrated by the confidence intervals (CIs) of the linear regression $\left(V \sim A, \mathrm{r}^{2}\right.$ adj $=$ 0.97, $\mathrm{p}<2.2 \times 10^{-16}$; Fig. 6 ). The low variance of the observed $R$, compared to those for $A$ and $V$, suggests that krill behave collectively to maintain a preferred swarm $R$ (Table. 1).

\section{Factors affecting swarm roughness}

All candidate GAMs describing the variation in krill swarm $R$ had a log-link function and a gamma-error distribution, which were selected so the model results would not violate model assumptions (Wood 2006). Various combinations of krill swarm descriptors
(Table 1) were considered as potential explanatory variables to explain variation in $R$ in the GAM (see Table 3 for an example subset of possible explanatory variable combinations), and the best GAM model was selected from candidate GAM models on the basis of lowest AIC (Table 3).

The best GAM explaining krill swarm $R$ was built of smooth functions (Fig. 5) of the following explanatory variables: swarm position in the water column $\left(\right.$ posn $\left._{\mathrm{wc}}, \mathrm{p}<2 \times 10^{-16}\right)$, mean swarm volume backscattering strength $\left(S_{\mathrm{v}}, \mathrm{p}<1.03 \times 10^{-10}\right)$, predator NND $\left(N N D_{\text {pred }}, \mathrm{p}=7.37 \times 10^{-11}\right)$ and NND between swarms $\left(N N D_{\text {swarm }}, \mathrm{p}=0.049\right)$. NNDs were the minimum 3DEuclidian distance between swarms, or between swarms and predators. Position in the water column
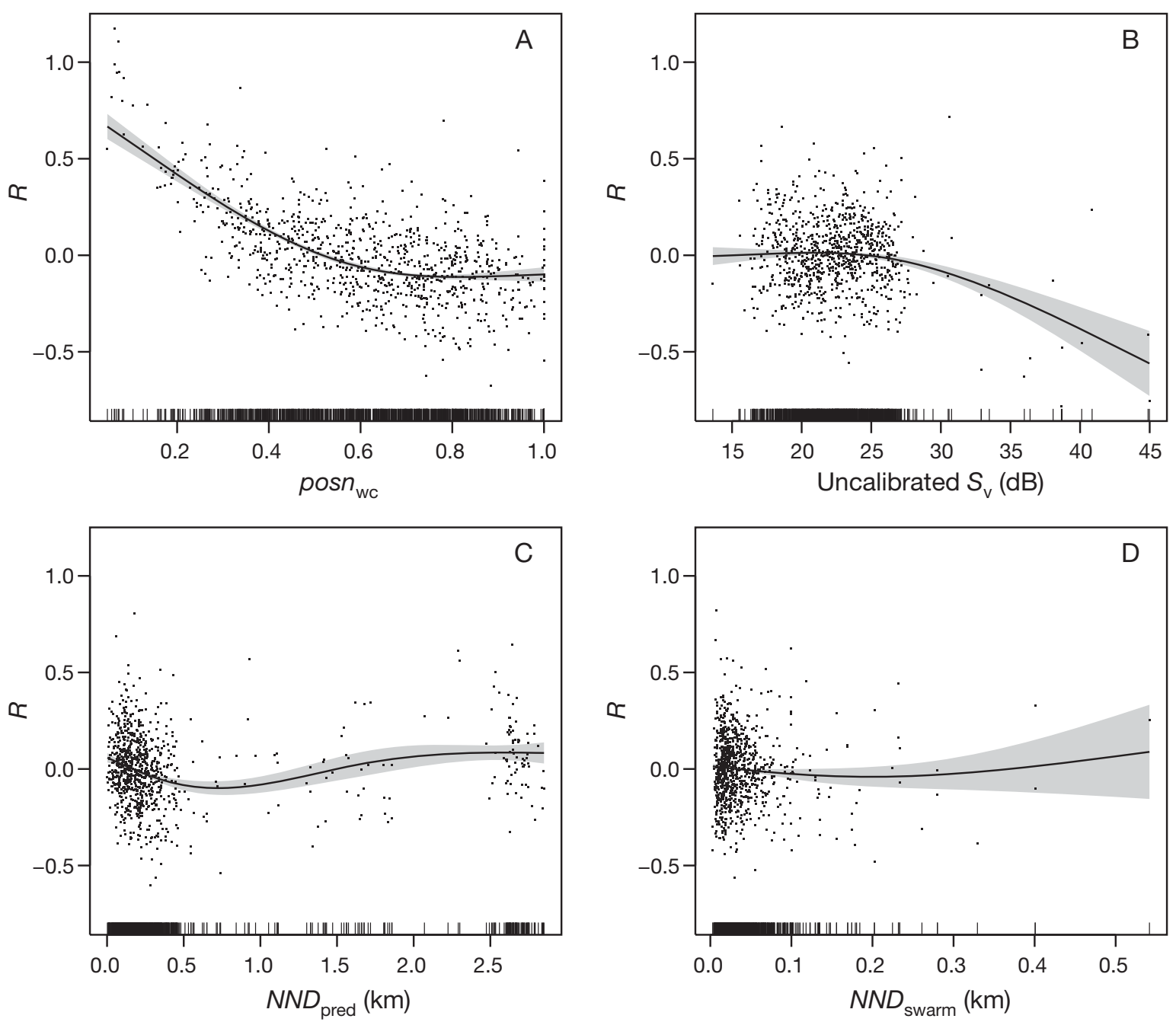

Fig. 5. Smooths of generalized additive modeling (GAM) terms showing the effect of various continuous variables on krill swarm roughness $(R)$. Locations of observations are shown as vertical lines on the $x$-axes. Solid lines are the estimates of the smooths, shaded areas are standard errors of the estimated smooths, and points are the observation partial residuals. (A) Position in water column $\left(\operatorname{posn}_{\mathrm{wc}}\right),(\mathrm{B})$ uncalibrated mean swarm volume backscattering strength $\left(S_{\mathrm{v}}\right)$, (C) predator nearest-neighbor distance $\left(N N D_{\text {pred }}\right)$ and (D) swarm nearest-neighbor distance $\left(N N D_{\text {swarm }}\right)$ 
was defined as $\operatorname{posn}_{\mathrm{wc}}=1-\left(\left|z_{\max }-z\right| / z\right)$, where $z=$ swarm depth and $z_{\max }=$ seabed depth. Thus, $0 \leq$ $\operatorname{posn}_{\mathrm{wc}} \leq 1$, and $\operatorname{posn}_{\mathrm{wc}}=1$ when the swarm was on the seabed. $\operatorname{posn}_{\mathrm{wc}}$ was used to provide a consistent measurement of the vertical location of swarm, since swarm depth and distance from the seabed were constrained by the actual seabed depth and could have represented the environment more than a behavior. The selected model explained $51.3 \%$ of the deviation in $R$, with $\mathrm{r}_{\text {adj }}^{2}=0.56$ (Table 3), demonstrating that the selected explanatory variables significantly influenced $R$ and were partially responsible for the variation in $R$ seen in Fig. 6.

The difference in AIC ( $\triangle$ AIC) between model 1 and model 2 was $<2$, indicating no discernible difference in these model fits (Burnham \& Anderson 2003). Since pred had no significant effect $(t$-value $=0.53$, Pr|t $\mid=$ 0.59 ) on $R$, model 2 was selected as the best model.

The smooth of $\operatorname{posn}_{\mathrm{wc}}$ shows that $R$ decreased as swarm depth increased with respect to seabed depth (i.e. as swarms got closer to the seabed; Fig. 5A). $R$ increased with higher swarm density $\left(S_{\mathrm{v}}>27 \mathrm{~dB}\right.$; Fig. 5B). The effect of the proximity of predators on swarm $R$ was significant: the model output shows that up to a distance of $0.5 \mathrm{~km}$ to the nearest predator, there was a decreasing linear relationship between the $N N D_{\text {pred }}$ and $R$ (Fig. 5 C), and for $N N D_{\text {pred }}>0.8 \mathrm{~km} R$ increased (Fig. 5C). $R$ decreased slightly with increasing $N N D_{\text {swarm }}$ (Fig. 5D).

\section{Krill predator-prey interactions}

Krill predator-prey interactions, observed by both the MBE-equipped RV 'Roald' and SBE-equipped RV 'Ernest', were evaluated as a function of range using the annulus sampling technique (Fig. 4). No relationship was detected between the mean number of SBE-detected swarms and distance from predator (Fig. 7). The mean numbers of MBE-observed and MBE-simulated swarms were significantly different (2-sample Kolmogorov-Smirnov test, $D=0.5667, \mathrm{p}=$ $1.4 \times 10^{-4}$ ) suggesting that predators were associated with areas of sea which contained an elevated number of swarms. The GAM-estimated smooth functions were used to fit curves to (1) the observed mean number of swarms counted around predator positions, and (2) the mean number of swarms counted around simulated predator positions (random positions) during the simulation exercise. The observed and simulated curves did not overlap, nor did the standard errors of the estimated smooths making up the curves, suggesting an increased number of swarms in the vicinity of predators than would be expected by chance (Fig. 7).

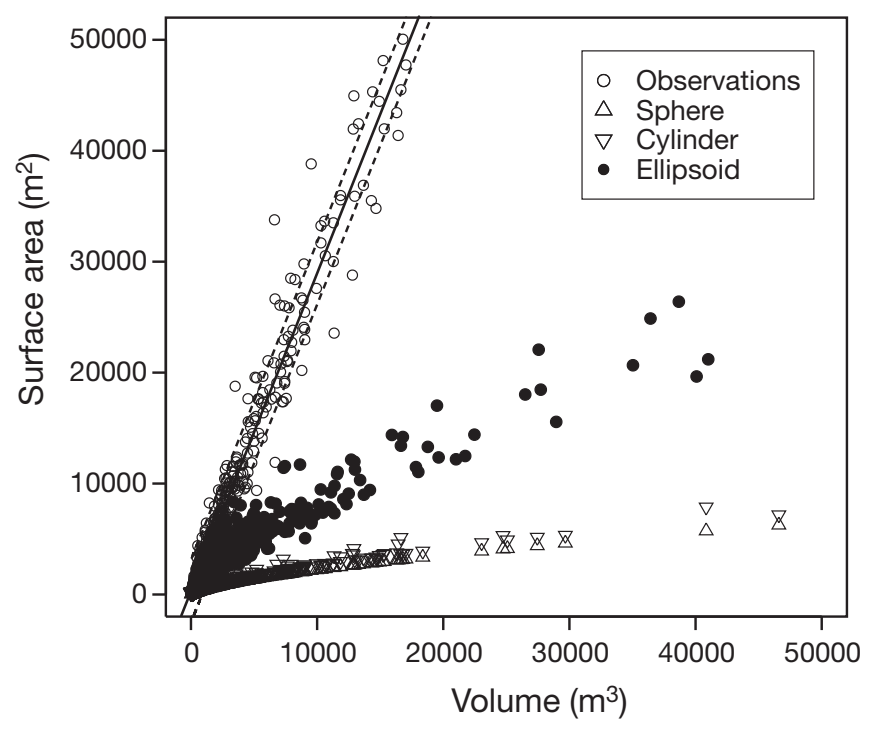

Fig. 6. Krill swarm roughness $(R=A / V)$, illustrated by observations of swarm volume $(V)$ and swarm surface area $(A)$, was compared to that of simple geometric shapes: spheres; cylinders, and ellipsoids. Observed krill swarm $R$ did not conform with that for these simple geometrical shapes. The linear regression $V \sim A\left(\mathrm{r}^{2}\right.$ adj $\left.=0.97, \mathrm{p}<2.2 \times 10^{-16}\right)$ is the solid line, and $95 \%$ CIs are the dashed lines



Fig. 7. Mean number of krill swarms around krill predator locations and simulation locations, as determined by the annulus sampler (see Fig. 4). The upper line is the estimated smooth and associated standard error (SE) for the mean number of swarms around 41 observed predator locations (see Table 2). The lower line is the mean estimated smooth and associated SE across the 1000 simulations, where each simulation comprised 41 randomly selected transect locations. For each simulation, a GAM smooth was fitted, and the line shown here for the simulations is the mean and standard deviation for all 1000 smooth curves. SBE: single-beam echosounder 


\section{DISCUSSION}

This study demonstrated that the SM20 $200 \mathrm{kHz}$ MBE system is capable of observing swarms of Antarctic krill in 3D. The arising 3D data provided 2 important insights regarding krill swarms in the nearshore environment: (1) krill in swarms exhibit a more or less constant roughness (Fig. 6) and, (2) air-breathing krill predators occupy areas of sea with higher than average numbers of krill swarms (Fig. 7).

\section{Krill swarm roughness: anti-predation behavior}

Previous investigations of krill swarms have provided evidence of behavioral mechanisms for swarm formation, with anti-predation and reproduction motivations being particularly important (Hewitt \& Demer 1993, Watkins \& Murray 1998, Lascara et al. 1999, Tarling et al. 1999). The rapid movements of individual krill may reduce their visibility to predators (O'Brien 1987), and individual krill within a swarm may quickly warn other krill throughout the swarm about a predator attack (O'Brien 1987, Krakauer 1995, Tarling et al. 2000).

Notwithstanding the many purported mechanisms underlying observed variations in krill swarm shape, it is observed here that one component of shape - the roughness - is quite constrained. The mean krill swarm roughness (mean $R=3.3$, coefficient of variation $=0.23)$ is remarkably similar to that seen for schools of clupeid fish off Venezuela and Senegal (mean $R=3.15$, coefficient of variation $=0.34$; Gerlotto \& Paramo 2003). The reason(s) for the similar roughnesses between these species remains unclear, and is the subject of our ongoing research. However, the $R \approx$ 3 is not a ubiquitous feature of pelagic species: in a different MBE investigation, Gerlotto et al. (2004) reported $R=5.7$ for schools of anchovy Engraulis ringens and common sardine Strangomera bentincki, and $R=$ 6.4 for layers (aggregations more diffuse than schools) of the same species.

Our MBE observations of krill swarms suggested that the aggregation roughness was influenced by predator presence (Fig. 5C), perhaps indicating anti-predation behaviors. These behaviors could include the dilution effect (reducing swarm density; O'Brien 1989), thereby reducing the predation risk of an individual krill in response to attack by a whale, or making it difficult for a penguin or seal to take individual krill (Landeau \& Terborgh 1986, Krakauer 1995, Krause \& Ruxton 2002).

Krill swarm roughness was also influenced by the $\operatorname{posn}_{\mathrm{wc}}$. It remains unclear why swarms became more spherical when located in the upper $70 \%$ of the water column, but in lower regions $\operatorname{posn}_{\mathrm{wc}}$ had no influence on $R$ (Fig. 5A). Since many predators routinely forage in the upper $30 \mathrm{~m}$ of the water column (e.g. Antarctic fur seals; Boyd et al. 1994), the influence of $\operatorname{posn}_{W C}$ on $R$ may also be due to anti-predation behavior.

Potentially, there is no standard response to the presence of predators by individual krill in a swarm. However, the variation in $R$ with respect to nearest predator distance (Fig. 5C) is perhaps evidence of a consistent response to predation by a swarm. This 'emergent property' suggests that individuals in a swarm must somehow communicate, perhaps through a wave of agitation (O'Brien 1989, Hofmann et al. 2004). No systematic variation in $R$ to the type of predator (flying versus swimming) was detected in the krill swarms we observed, perhaps because no difference existed or because the predator sample size was too small to detect one with statistical significance. If there is a different response yet to be detected, it could be a function of the life-stage of krill constituting the swarm (Watkins et al. 1992 suggested size/sex segregation in swarms), or the type of attack. Or there may be only one type of response by a swarm to predation. Whatever the truth, MBE observations offer a powerful means to further investigate the phenomenon.

\section{Predator-prey interactions}

Combining MBE observations with visual observations of krill predators has enabled the study of predatorprey interactions in a manner that reveals small-scale spatial behavior likely undetectable by a conventional SBE system. The elevated number of swarms detected by the MBE in the vicinity of predator sightings suggests either that predators are targeting areas with a large number of krill swarms, or that krill swarms are splitting in response to predator presence (Fig. 7). This spatial association was not evident in SBE data (Fig. 7), perhaps explaining why previous studies (e.g. Logerwell et al. 1998) failed to show significant predator-prey association. To determine whether swarms are splitting in response to predation or predators are targeting areas of higher krill biomass, estimates of krill density are needed. While acoustic target strength models and measurements are available for krill insonified from dorsal to lateral aspect (e.g. Hewitt \& Demer 1996, Demer \& Conti 2005, Conti \& Demer 2006), the MBE was not calibrated and so it remains difficult to convert echo intensities to numerical densities. Moreover, because the krill swarms were not of uniform density (see $S_{\mathrm{v}}$ means, Table 1), the swarm volume in an annulus-sampling area could not be used as a proxy for krill biomass. It is clear that the elevated number of swarms detected by the MBE in the vicinity of predators ( 0 to ca. $150 \mathrm{~m}, \mathrm{x}$-axis, Fig. 7) was not a sampling artifact caused by the geometry of the MBE swath (\#2 in Fig. 1) or the annulus 
sampling regions (Fig. 4). If the curve of mean observed number of swarms (Fig. 7) was driven by geometry alone, then the mean observed number of swarms and the mean simulated number of swarms curves would have overlapped.

\section{Multibeam echosounder utility}

An advantage of using an MBE over the SBE is that the volume and surface area of pelagic aggregations can be observed directly, rather than derived from an assumed 3D shape. Simmonds \& MacLennan (2005) presented a statistical technique that enabled the mean area of an aggregation to be determined from SBE observations by assuming that aggregations have a circular horizontal cross-section (i.e. assuming either spherical or cylindrical shapes). Here it is shown that in the case of krill swarms, neither assumption is valid. While the ellipsoid had the closest roughness to the MBE-observed roughness (Fig. 6), the ellipsoid requires 3 length measurements to approximate area and volume, whereas only swarm length and height are available from SBE observations. This finding indicates that extrapolation of SBE observations to 3D cannot be used to estimate swarm shape or roughness.

\section{CONCLUSIONS}

This investigation has demonstrated that krill swarms can be detected and described in 3D with a $200 \mathrm{kHz} \mathrm{MBE}$, and that the external envelope of krill swarms cannot be accurately described by simple geometric shapes. It appears that krill swarms maintain a similar roughness irrespective of shape, perhaps as a response to predator presence. The increased sampling volume of the MBE compared to the SBE used in this investigation revealed a previously undetected elevated number of krill swarms in the vicinity of airbreathing predators.

Acknowledgements. We thank the Royal Society for funds enabling deployment of the MBE; Simrad USA, particularly Jeff Condiotty, for the loan of the SM20, and D. Needham and M. Patterson of Sea Technology Services for designing and constructing the transducer mount. We are grateful to the United States Antarctic Marine Living Resources Program; the Master, officers and crew of the RV 'Yuzhmorgeologiya', and the personnel at the Cape Shirreff field station for logistical, equipment and ship support. M.J.C. was supported by a NERC PhD studentship. This work was carried out in association with an NSF-funded (grant \#06-OPP-33939) investigation of the Livingston Island nearshore environment. We thank A. Jenkins, T. S. Sessions and M. van den Berg for skippering the nearshore boats, and T. S. Sessions for providing invaluable expertise in the field.

\section{LITERATURE CITED}

Akaike H (1974) A new look at the statistical model identification. IEEE Trans Automat Contr 19:716-723

Atkinson A, Whitehouse MJ, Priddle J, Cripps GC, Ward P, Brandon MA (2001) South Georgia, Antarctica: a productive, cold water, pelagic ecosystem. Mar Ecol Prog Ser 216: 279-308

Axelsen BE, Anker-Nilssen T, Fossum P, Kvamme C, Nøttestad L (2001) Pretty patterns but a simple strategy: predatorprey interactions between juvenile herring and Atlantic puffins observed with multibeam sonar. Can J Zool 79: 1586-1596

Boyd IL, Arnould JPY, Barton T, Croxall JP (1994) Foraging behaviour of Antarctic fur seals during periods of contrasting prey abundance. J Anim Ecol 63:703-713

Brierley AS, Ward P, Watkins JL, Goss C (1998) Acoustic discrimination of Southern Ocean zooplankton. Deep-Sea Res II 45:1155-1173

Brierley AS, Watkins JL, Goss C, Wilkinson MT, Everson I (1999) Acoustic estimates of krill density at South Georgia, 1981 to 1998 . CCAMLR Sci 6:47-57

Burnham KP, Anderson DR (2003) Model selection and multimodel inference: a practical information-theoretic approach, 2nd edn Springer, New York

Constable AJ, de la Mare WK, Agnew DJ, Everson I, Miller D (2000) Managing fisheries to conserve the Antarctic marine ecosystem: practical implementation of the Convention on the Conservation of Antarctic Marine Living Resources (CCAMLR). ICES J Mar Sci 57:778-791

Conti SG, Demer DA (2006) Improved parameterization of the SDWBA for estimating krill target strength. ICES J Mar Sci 63:928-935

Cox MJ (2008) Acoustic and ecological investigations into predator-prey interactions between Antarctic krill (Euphausia superba) and seal and bird predators. PhD thesis, University of St. Andrews, Fife

Cox MJ, Warren JD, Demer DA, Cutter GR, Brierley AS (2009) Three-dimensional observations of Antarctic krill (Euphausia superba) swarms made using a multi-beam echosounder. Deep-Sea Res II (in press)

Demer DA, Conti SG (2005) New target-strength model indicates more krill in the Southern Ocean. ICES J Mar Sci 62: 25-32

- Gerlotto F, Paramo J (2003) The three-dimensional morphology and internal structure of clupeid schools as observed using vertical scanning multibeam sonar. Aquat Living Resour 16:113-122

Gerlotto F, Soria M, Freon P (1999) From two dimensions to three: the use of multibeam sonar for a new approach in fisheries acoustics. Can J Fish Aquat Sci 56:6-12

> Gerlotto F, Castillo J, Saavedra A, Barbieri MA, Espejo M, Cotel P (2004) Three-dimensional structure and avoidance behaviour or anchovy and common sardine schools in central Chile. ICES J Mar Sci 61:1120-1126

Gorska N, Ona E (2003) Modelling the acoustic effect of swimbladder compression in herring. ICES J Mar Sci 60: 548-554

$>$ Hewitt RP, Demer DA (1993) Dispersion and abundance of Antarctic krill in the vicinity of Elephant Island in the 1992 austral summer. Mar Ecol Prog Ser 99:29-39

Hewitt RP, Demer DA (1994) Acoustic estimates of krill biomass in the Elephant Island area: 1981-1993. CCAMLR Sci 1:1-5

> Hewitt RP, Demer DA (1996) Lateral target strength of Antarctic krill. ICES J Mar Sci 53:297-302

> Hewitt RP, Demer DA (2000) The use of acoustic sampling to estimate the dispersion and abundance of euphausiids, 
with an emphasis on Antarctic krill, Euphausia superba. Fish Res 47:215-229

Hewitt RP, Demer DA, Emery JH (2003) An 8-year cycle in krill biomass density inferred from acoustic surveys conducted in the vicinity of the South Shetland Islands during the austral summers of 1991-1992 through 2001-2002. Aquat Living Resour 16:205-213

Hewitt RP, Watkins J, Naganobu M, Sushin V and others (2004) Biomass of Antarctic krill in the Scotia sea in January/February 2000 and its use in revising an estimate of precautionary yield. Deep-Sea Res II 51:1215-1236

Hofmann EE, Haskell AGE, Klinck JM, Lascara CM (2004) Lagrangian modelling studies of Antarctic krill (Euphausia superba) swarm formation. ICES J Mar Sci 61:617-631

Krakauer DC (1995) Groups confuse predators by exploiting perceptual bottlenecks: a connectionist model of the confusion effect. Behav Ecol Sociobiol 36:421-429

Krause J, Ruxton GD (2002) Living in groups. Oxford University Press, Oxford

Landeau L, Terborgh J (1986) Oddity and the confusion effect in predation. Anim Behav 34:1372-1380

Lascara CM, Hofmann EE, Ross RM, Quetin LB (1999) Seasonal variability in the distribution of Antarctic krill, Euphausia superba, west of the Antarctic Peninsula. Deep-Sea Res I 46:951-984

Logerwell EA, Hewitt RP, Demer DA (1998) Scale-dependent spatial variance patterns and correlations of seabirds and prey in the southeastern Bering Sea as revealed by spectral analysis. Ecography 21:212-223

Mangel M, Nicol S (2000) Krill and the unity of biology. Can J Fish Aquat Sci 57:1-5

O'Brien DP (1987) Description of escape responses of krill (Crustacea: Eupausiacea), with particular reference to swarming behavior and the size and proximity of the predator. J Crustac Biol 7:449-457

O'Brien DP (1989) Analysis of the internal arrangement of individuals within crustacean aggregations (Eupausiacea, Mysidacea). J Exp Mar Biol Ecol 128:1-30

Paramo J, Bertrand S, Villalobos H, Gerlotto F (2007) A three-

Editorial responsibility: Rory Wilson,

Swansea, UK dimensional approach to school typology using vertical scanning multibeam sonar. Fish Res 84:171-179

R Development Core Team (2007). R: a language and environment for statistical computing. R Foundation for Statistical Computing, Vienna

Reid DG, Simmonds EJ (1993) Image analysis techniques for the study of fish school structure from acoustic survey data. Can J Fish Aquat Sci 50:886-893

Reiss CS, Cossio AM, Loeb V, Demer DA (2008) Variations in the biomass of Antarctic krill (Euphausia superba) around the South Shetland Islands, 1996-2006. ICES J Mar Sci 65: 497-508

Simmonds JE, MacLennan DN (2005) Fisheries acoustics: theory and practice, 2nd edn Chapman \& Hall, London

Tarling GA, Cuzin-Roudy J, Buchholz F (1999) Vertical migration behaviour in the northern krill Meganyctiphanes norvegica is influenced by moult and reproductive processes. Mar Ecol Prog Ser 190:253-262

Tarling G, Burrows M, Matthews J, Saborowski R, Buchholz F, Bedo A, Mayzaud P (2000) An optimisation model of the diel vertical migration of northern krill (Meganyctiphanes norvegica) in the Clyde Sea and the Kattegat. Can J Fish Aquat Sci 57(S3):38-50

Venables WN, Dichmont CM (2004) GLMs, GAMs and GLMMs: an overview of theory for applications in fisheries research. Fish Res 70:319-337

Watkins JL, Murray AWA (1998) Layers of Antarctic krill, Euphausia superba: are they just long krill swarms? Mar Biol 131:237-247

Watkins JL, Buchholz F, Priddle J, Morris DJ, Ricketts C (1992) Variation in reproductive status of Antarctic krill swarms; evidence of size-related sorting mechanism? Mar Ecol Prog Ser 82:163-174

Wood SN (2006) Generalized additive models: an introduction with R. Chapman \& Hall, London

Zamon JE, Greene CH, Meir E, Demer DA, Hewitt RP, Sexton $S$ (1996) Acoustic characterization of the three-dimensional prey field of foraging chinstrap penguins. Mar Ecol Prog Ser 131:1-10

Submitted: October 8, 2007; Accepted: October 23, 2008

Proofs received from author(s): March 11, 2009 